Article

\title{
Variation of Projected Atmospheric Water Vapor in Central Asia Using Multi-Models from CMIP6
}

\author{
Zhenjie Li ${ }^{1,2,3}$, , Hui Tao ${ }^{1}$, Heike Hartmann ${ }^{4}$, Buda Su ${ }^{1,5, *}$, Yanjun Wang ${ }^{1,6}$ and Tong Jiang ${ }^{1,6, *}$ \\ 1 State Key Laboratory of Desert and Oasis Ecology, Xinjiang Institute of Ecology and Geography, Chinese \\ Academy of Sciences, Urumqi 830011, China; lizhenjie191@mails.ucas.ac.cn (Z.L.); \\ taohui@ms.xjb.ac.cn (H.T.); wangyj@nuist.edu.cn (Y.W.) \\ 2 University of Chinese Academy of Sciences, Beijing 100011, China \\ 3 Lincang Meteorological Bureau, Lincang Yunnan 677099, China \\ 4 Department of Geography, and the Environment, Slippery Rock University, Slippery Rock, PA 16057, USA; \\ heike.hartmann@sru.edu \\ 5 National Climate Center, China Meteorological Administration, Beijing 100081, China \\ 6 Collaborative Innovation Center on Forecast and Evaluation of Meteorological Disasters/Institute for \\ Disaster Risk Management/School of Geographical Sciences, Nanjing University of Information Science \& \\ Technology, Nanjing 210044, China \\ * Correspondence: subd@cma.gov.cn (B.S.); jiangtong@nuist.edu.cn (T.J.)
}

Received: 19 July 2020; Accepted: 25 August 2020; Published: 26 August 2020

Abstract: Using data from the Integrated Global Radiosonde Archive Version 2 (IGRA2) and the Multi Model Ensemble (MME) of four global climate models (GCMs), named CanESM5, IPSL-CM6A-LR, MIROC6, and MRI-ESM2-0, within the framework of phase 6 of the Coupled Model Intercomparison Project (CMIP6), we analyzed the changes in atmospheric total column water vapor (TCWV) over Central Asia in the future (2021-2100) under SSP-RCPs scenarios: SSP1-1.9, SSP1-2.6, SSP2-4.5, SSP3-7.0, SSP4-3.4, SSP4-6.0, and SSP5-8.5, relative to baseline period (1986-2005). Results showed that the annual mean TCWV from IGRA2 was consistent with the model output from 1979 to 2014 in Central Asia. Besides, the spatial distribution of TCWV in Central Asia during the baseline period was consistent between the models. The regional average value of Central Asia was between 10.8 $\mathrm{mm}$ and $12.4 \mathrm{~mm}$, and decreased with elevation. TCWV will increase under different SSP-RCPs from 2021 to 2040, but showed different trends after 2040. It will increase under SSP1-1.9 and SSP1-2.6 scenarios from 2021 to 2050, and decrease after that. It will grow from 2021 to 2055 under SSP4-3.4 scenario, and then stay essentially constant. Under SSP2-4.5 and SSP4-6.0 scenarios, TCWV will rise rapidly during 2021-2065, but the growth will decline from 2065 to 2100 . TCWV will continue to increase under SSP3-7.0 and SSP5-8.5 scenarios, and the largest increase is projected under SSP5-8.5 scenario. Change in near-surface temperature (Ts) matched the change in TCWV, but changes in precipitation and evapotranspiration are not significant during 2021-2100. In spite of the large variations in TCWV under different SSP-RCPs, the dominant characteristic in all scenarios shows that a large TCWV increase is demonstrated over areas with small TCWV amounts during the baseline period. On the contrary, increases will be small where the TCWV amounts had been large during the baseline period. The change in TCWV is highly correlated to the increase in Ts in Central Asia. Under SSP2-4.5, SSP3-7.0, SSP4-3.4, SSP4-6.0, and SSP5-8.5 scenarios, the higher the temperature due to higher radiative forcing, the steeper the regression slope between TCWV and Ts change. It is closest to the theoretical value of the Clausius-Clapeyron equation under SSP3-7.0 and SSP5-8.5 scenarios, but not presented under other scenarios. Spatially, steeper regression slopes during 2021-2100 have been found around the Caspian Sea in the southwest and in the high-elevation areas in the southeast of Central Asia, which is likely related to the abundant local water supply for evaporation.

Keywords: total column water vapor; CMIP6 models; SSP-RCP scenarios; Central Asia 


\section{Introduction}

Global warming is a widely accepted phenomenon; despite being complex, it has become a global research hotspot since the last century. According to the fifth assessment report of Intergovernmental Panel on Climate Change (IPCC), the global mean surface air temperature will rise $2.6 \sim 4.8^{\circ} \mathrm{C}$ by the end of the 21st century under the Representative Concentration Pathway (RCP) 8.5 [1]. This would cast a tremendous impact on the global and regional climate [2], and can change the mechanism of moisture circulation between oceans and continents. The rising temperatures can lead to increased evapotranspiration, which means more water vapor entering the atmosphere and being held, and the hydrological cycle could become more active [3]. The atmospheric water vapor content is of special importance to the formation of precipitation, which plays a crucial role in radiation balance and the hydrological cycle in the climate system [4-8]. The atmospheric water vapor can condense to form clouds, which influence the heating rate and circulation greatly, and strongly affects the cloud properties and their spatial and vertical distribution, thereby potentially affecting the atmospheric column and surface radiation energy budgets [6]. The water vapor is the most abundant greenhouse gas (GHG) in the atmosphere, and can amplify the effect of other GHGs through positive feedback [9]. The atmospheric boundary layer, which is the lowest portion of the troposphere, is in contact with the source of water in the Earth's oceans, and on its land surfaces, holds most of the atmospheric moisture. Increased evapotranspiration due to global warming may also result in a reduction to land surface water supplies and cause local droughts [10]. The atmospheric water vapor has high spatial and temporal variability [11]. Globally, it is certain that the troposphere has warmed since the mid-20th century, and likewise, the global near surface and tropospheric air specific humidity have also increased since the 1970s [12]. The tropospheric specific humidity has increased about $3.5 \%$ in the past 40 years, which is consistent with the observed temperature change of about $0.5^{\circ} \mathrm{C}$ during the same period [1]. Global warming can increase the melting intensity of glacial cover of the planet that could lead to significant changes in the global water cycle [13].

The water vapor change can be attributed to human influence with medium confidence. Thus, it is important to investigate the long-term changes in atmospheric water vapor and their relationship with temperature, for a better understanding of future climate changes $[6,8]$. For simulations of past, current, and future climate trends and variability, the Coupled Model Intercomparison Project (CMIP) has become one of the fundamental elements of climate science [14], and a central pillar of national and international assessments of climate change [12]. Consisting of historical simulations and future climate changes given internal climate variability, predictability, and uncertainties in scenarios, Phase 6 of the Coupled Model Intercomparison Project (CMIP6) was designed to fill the scientific gaps of the previous CMIP5. One of its objectives is to better understand past (1850-near present), present, and future (2015-2100 or 2300) climate change arising from natural, unforced variability, or in response to changes in radiative forcing in a multi-model context. The comprehensive assessment model, based on a new approach to future social development, combines the Shared Socioeconomic Pathways (SSPs) with RCPs, and is called the Scenario Model Intercomparison Project (ScenarioMIP), it's the primary activity within CMIP6, that will support multi-model climate projections based on alternative scenarios of future emissions and land use changes produced with integrated assessment models [15-17]. It provides a new set of emissions and land use scenarios based on the SSPs, and the forcing level usually refers to the forcing achieved in 2100 [18]. Compared with the scenarios only concerning various emission conditions designed in CMIP5, the ScenarioMIP in CMIP6 is designed with combinations of socioeconomic developments and the feedback of global climate changes. The improvements of CMIP6 were not only retains the four typical emission paths of CMIP5 (RCP2.6, RCP4.5, RCP6.0, and RCP8.5), but also adds three new emission paths, RCP1.9, RCP3.4, and RCP7.0 [19]. The new scenarios combine SSP1, SSP2, SSP3, SSP4, and SSP5 of five socio-economic paths, with the emission intensity of $1.9 \mathrm{~W} \mathrm{~m}^{-2}, 2.6 \mathrm{~W} \mathrm{~m}^{-2}, 3.4 \mathrm{~W} \mathrm{~m}^{-2}, 4.5 \mathrm{~W} \mathrm{~m}^{-2}, 6.0 \mathrm{~W} \mathrm{~m}^{-2}, 7.0 \mathrm{~W} \mathrm{~m}^{-2}$, and $8.5 \mathrm{~W} \mathrm{~m}^{-2}$, to form seven future SSP-RCP scenarios, including SSP1-1.9 (represents the very low end of the range of scenarios), SSP1-2.6 (combination of low societal vulnerability and low forcing level), SSP2-4.5 (combination of 
intermediate societal vulnerability and intermediate forcing level), SSP3-7.0 (combination of relatively high societal vulnerability and relatively high forcing level), SSP4-3.4 (fills a gap at the low end of the range of future forcing pathways with intermediate societal vulnerability), SSP4-6.0 (fills in the range of medium forcing pathways with intermediate societal vulnerability), and SSP5-8.5 (combination of high societal vulnerability and high forcing level). The new scenarios are part of the preparation of the Sixth Assessment Report (AR6) of the IPCC [16-19]. The types of model experiments to be run by the CMIP6 climate model groups divided into two tiers differentiated by priority-Tier 1 and Tier 2 respectively. Tier 1 includes RCP2.6, RCP4.5, and RCP8.5 forcing levels, and an additional forcing scenario (SSP3-7.0), with particularly high aerosol emissions and land use change. Tier 2 includes additional scenarios of interest, as well as additional ensemble members and long-term extensions. A more detailed depiction of each scenario and its rationale in $\mathrm{O}^{\prime} \mathrm{Neill}$ et al. (2016) [15].

Central Asia is located far from the ocean, and moisture advection is low. During the past four decades, Central Asia has seen remarkable warming: the near surface air temperature (Ts) has increased rapidly since the $1970 \mathrm{~s}$ [2,20], at a rate of $0.36-0.42^{\circ} \mathrm{C}$ per 10 years from 1979 to 2011 [21]. Climate change can significantly affect the distribution of water resources in space and time, and also affect the amount of water resources, as has been proven by many scientific studies. Atmospheric moisture is an important part of the water cycle, and plays a particularly important role in the energy balance, the material migration and the ecological system in the arid and semi-arid regions. In some extreme arid regions, it has become an element that restricts social development, with the fragile ecological environment depending on it. In view of these, this study focuses on the variation of the atmospheric total column water vapor (TCWV) in Central Asia. It is not only the average state of the atmospheric TCWV that is of relevance-the decadal variations and the spatial and temporal distribution in Central Asia need to be studied indeed. According to the traditional Clausius-Clapeyron relationship, the atmospheric water vapor increases by roughly $7 \%$ per degree Celsius of global warming [22]. Whether this relationship applies to the atmospheric water vapor in Central Asia, will be reflected in this study. Numerous studies and observations revealed that surface humidity and tropospheric humidity were increasing with the increase of atmospheric temperature over the last several decades [12,23]. Therefore, it is necessary to study the relationship between TCWV and temperature in utilizing future climate models. At present, the changes in the relationship between TCWV and Ts in Central Asia have not been studied by using models from CMIP6.

The outline of the paper is organized as follows. Section 2 presents the study area and the data sets used in this study. To compare the observed and CMIP6 data, interpretations of the spatial characteristics and temporal variations of TCWV in past and in future (2021-2100) in Central Asia are shown in Section 3. A summary and concluding remarks are presented in Section 4.

\section{Study Area and Data}

\subsection{Study Area}

Central Asia (Figure 1) is located in the hinterland of the Eurasian continent, with an area of $3.882 \times 10^{4} \mathrm{~km}^{2}$. The population is about 60 million in five countries: Uzbekistan, Turkmenistan, Kyrgyzstan, Tajikistan, and Kazakhstan [24,25]. The study region in this paper is defined between $35-55^{\circ} \mathrm{N}$ and $50-80^{\circ} \mathrm{E}$, including oases, deserts, mountains, hills and plains, with a mean elevation of $1206 \mathrm{~m}$ above sea level [26]. The Central Asian countries are located in the arid and semi-arid climate zone. The climate is continental, with scarce precipitation and high evapotranspiration, where without irrigation, it is impossible to cultivate and to sustain crops. There are great changes in topography and landforms in Central Asia, and water resources are unevenly distributed in space and time. There are many lakes in the mountains and plains of Central Asia, such as the Caspian Sea, and Lakes Aral and Balkhash. Central Asia has approximately $170-180 \mathrm{~km}^{3}$ of surface water resources, and more than $90 \%$ of it is used for irrigation [13]. Lack of water resources restricts the productivity in the industry and agriculture sectors, and affects the relationship between the five countries. Most rivers originate in 
the high elevation mountains of Central Asia, with most of the runoff supplied by glacial and snow melt. The glaciers of Central Asia occupy an area of $17,950 \mathrm{~km}^{2}$ and unevenly distributed over the territories of the Central Asian countries [27]. Glaciers melt, especially during the summer, and climate change and intensive irrigation affect the state of glaciers. Asian glaciers have been melting since the 1960s at a constant rate, due to the increase in temperature. As in many other parts of the world, glaciers in the Tien-Shan mountains have been retreating since the end of the Little Ice Age (LIA) in the mid-nineteenth century, a tendency that has accelerated since the 1970s [28]. The total amount of fresh water in Central Asia is about $1.09 \times 10^{12} \mathrm{~m}^{3}$, however, the usable water resources are only about $2.66 \times 10^{11} \mathrm{~m}^{3}$, of which surface water is about $2.38 \times 10^{11} \mathrm{~m}^{3}[29,30]$. Understanding climate change in Central Asia is of great significance to advocate right decisions about the use of water in response to climate change.

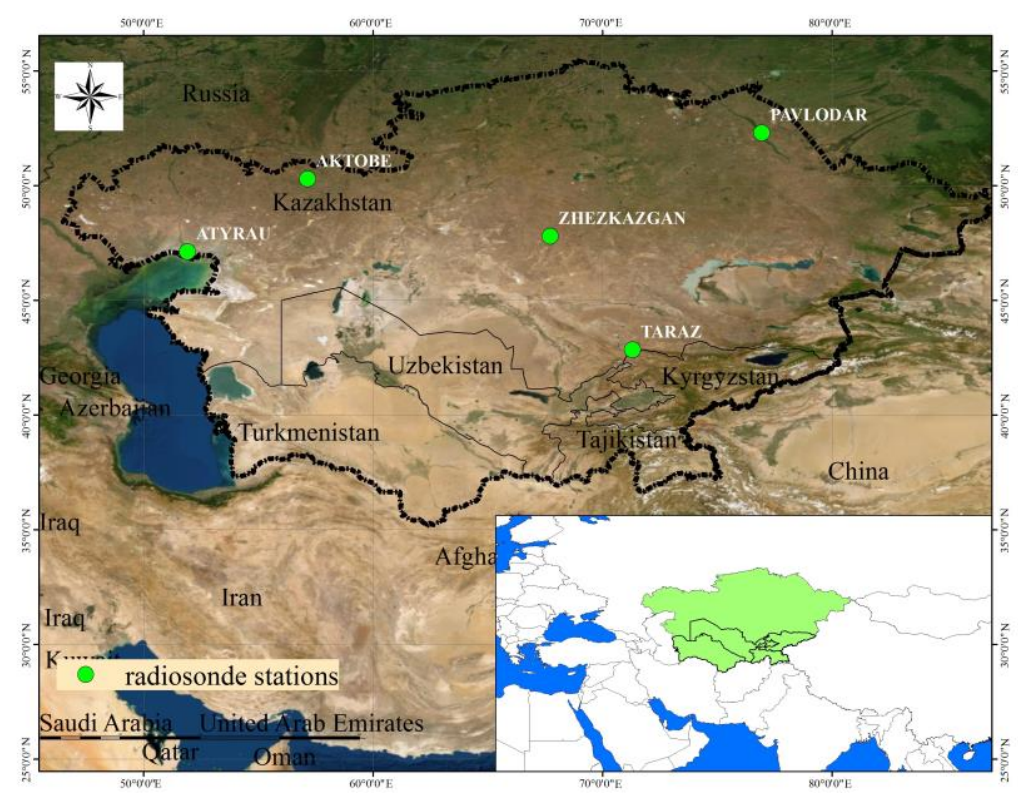

Figure 1. Topography andradiosonde stations in Central Asia.

\subsection{IGRA Data}

In situ observations are undoubtedly the most valuable reference for measuring the performance of reanalysis products and climate models. However, two realistic limitations are that their spatial coverage is extremely limited, and that temporal continuity is too short. For this study, the radiosonde data derived from the Integrated Global Radiosonde Archive Version 2 (IGRA2) are used. IGRA2 replaces IGRA Version 1 as the baseline upper-air dataset produced by the National Oceanic and Atmospheric Administration (NOAA)/National Climate Data Center (NCDC), and updated in August 2016. The IRGA2 data contain more than 2000 globally distributed radiosonde stations. There are few IGRA2 stations in Central Asia. According to the data quality, we chose five sites, as is shown in Figure 1. More information about the radiosonde stations is described by Jie Jiang [31].

The daily 00:00 (UTC, same below) and 12:00 detection results, including temperature, pressure, geopotential height, relative humidity, dew point depression, wind direction and speed, are provided at 11 standard pressure levels $(1000,925,850,700,500,400,300,250,200,150$ and $100 \mathrm{hPa})$. All data have gone through a strict quality control process. The monthly means are computed using the daily data over the period from 1979 to 2014. 
The TCWV is calculated by integrating the specific humidity from radiosonde observations from the surface to $300 \mathrm{hPa}$, using the formula expressed as below:

$$
\mathrm{TCWV}=-\frac{1}{g} \int_{p_{s}}^{p_{0}} q d p \approx-\frac{1}{g} \sum_{p_{s}}^{p_{0}} q_{i} \Delta p_{i}
$$

where TCWV is the vertically integrated water vapor from the ground surface $\left(p_{s}\right)$ to $\mathrm{p}_{0} ; p_{\mathrm{s}}$ is the surface air pressure in $\mathrm{hPa} ; p_{0}$ is set to be $300 \mathrm{hPa} ; g\left(=9.8 \mathrm{~m} \mathrm{~s}^{-2}\right)$ is the gravitational acceleration; $i$ is the isobaric layer, $q$ is the specific humidity, and $p$ is the air pressure in hPa. In practice, as the right half of the formula (1), it is generally calculated by summing the difference of specific moisture on each standard isobaric surface of sounding observation [32]. Since IGRA2 contains the vapor pressure only, we calculated specific humidity using the following formula [33]:

$$
q=-0.622 \frac{e}{p-0.379 e}
$$

where $q\left(\mathrm{~kg} \mathrm{~kg}^{-1}\right)$ is the specific humidity, $e$ is the vapor pressure in $\mathrm{hPa}$ and $p$ is the air pressure at each level.

\subsection{CMIP6 Data}

At the time of writing (June 2020), there were only four global climate models (GCMs) containing all of the seven SSPs-RCPs scenarios that had become available from CMIP6. Therefore, the pivotal focus of this study is to cover all the seven SSPs-RCPs scenarios, rather than the number of models. The CMIP6 four models used in this study are listed in Table 1 together with their horizontal resolution. For comparison purposes, all datasets were interpolated to the same resolution, $0.5^{\circ} \times 0.5^{\circ}$, using the bilinear interpolation method. These models include both retrospective all-forcing historical climate simulations (with specified anthropogenic and natural external forcing) from 1850 to 2014, and the future projection period is 2015-2100. The TCWV outputs from the four CMIP6 models (Table 1) were analyzed in this study, and only the first ensemble run ("r1i1p1f1") is used here if a model had multiple ensemble simulations.

Table 1. Summary of the four Coupled Model Intercomparison Project (CMIP6) models used in this study.

\begin{tabular}{ccc}
\hline Model Name & Horizontal Resolution (Lon $\times$ Lat) & Modeling Center \\
\hline CanESM5 & $\sim 2.8^{\circ} \times 2.8^{\circ}$ & Canadian Centre for Climate Modelling \\
and Analysis, Canada \\
IPSL-CM6A-LR & $2.5^{\circ} \times 1.2676^{\circ}$ & IPSL, France \\
MIROC6 & $1.4063^{\circ} \times 1.40^{\circ}$ & AORI-UT-JAMSTEC-NIES, Japan \\
MRI-ESM2-0 & $\sim 1.125^{\circ} \times 1.12^{\circ}$ & MRI, Japan \\
\hline
\end{tabular}

In this study, seven scenarios, as shown in Figure 2, have been selected for analysis. Compared with the scenarios of CMIP5, SSP1-1.9, SSP4-3.4, and SSP3-7.0 in CMIP6 are updated emission and land use scenarios [19]. The historical simulation period of the four models is 1850-2014, and the future projection period is 2015-2100. In this paper, the period from 1986 to 2005 was determined as the baseline period for the comparative analysis of future projections, including the analysis of changes in water vapor in the whole atmospheric column, in near surface temperature, precipitation, and evapotranspiration under different scenarios. Projections of responses to scenarios, and associated impacts, may use a more recently commonly used reference period, which can counteract historical observations and avoid uncertainty in past and future changes. Moreover, two recent baseline periods are used in the Special Report on Global Warming of $1.5^{\circ} \mathrm{C}$ : 1986-2005 and 2006-2015 (global surface mean temperature in 1986-2005 was $0.61^{\circ} \mathrm{C}$ warmer than the preindustrial levels [34]). Therefore, we 
selected 1986-2005 as the baseline period, which is a more scientifically meaningful choice, especially as it was frequently used in the fifth assessment report of IPCC [15].

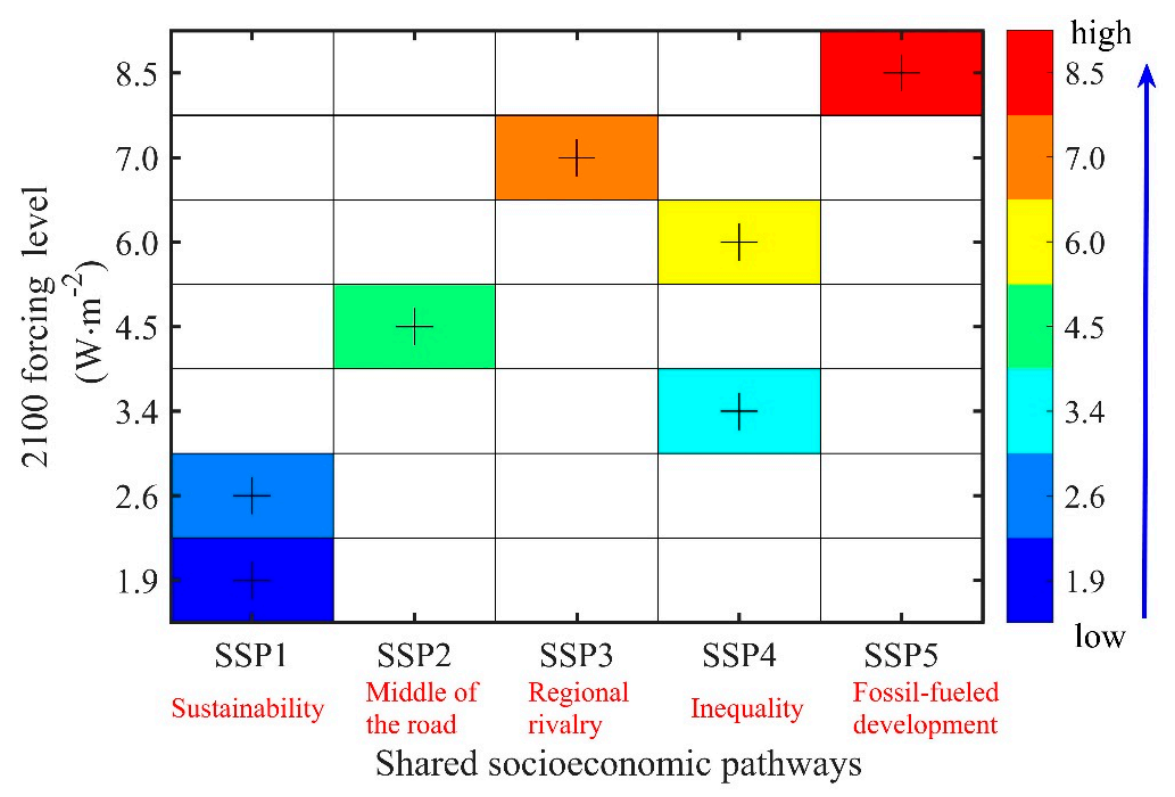

Figure 2. SSP-RCP scenarios matrix illustrating ScenarioMIP simulations (indicated by different colors). Each cell in the matrix indicates a combination of Shared Socioeconomic Pathways (SSPs) and the Representative Concentration Pathways (RCPs). The vertical represents the future level of radiation forcing, and the forcing level usually refers to the forcing reaching in 2100 . The seven values of rows represent radiation levels achieved $1.9,2.6,3.4,4.5,6.0,7.0$ and $8.5 \mathrm{~W} \mathrm{~m}^{-2}$ respectively by the end of the 21st century, and they are represented by different colors (i.e., blue is $1.9 \mathrm{~W} \mathrm{~m}^{-2}$, light blue is $2.6 \mathrm{~W} \mathrm{~m}^{-2}$, and bright red is $8.5 \mathrm{~W} \mathrm{~m}^{-2}$, and so on). Five columns represent five different SSPs and are marked red on the bottom of the panel. The colored cells represent seven SSP-RCP scenarios used in this study.

\section{Results and Discussion}

\subsection{Evaluation of Historical TCWV Based on Radiosonde Observations}

The TCWV values were calculated using observational data from five sounding stations in Central Asia, and compared with the simulation data from GCMs for 1979-2014. The period selected in Figure 3 is during 1979-2014, and it contained 432 months of data. In Figure 3, each point presents a month's data-the average of the daily 00:00 and 12:00 IGRA2 data, $n$ represents the number of months actually used for comparison. The linear correlation analysis of IGRA2 data and CMIP6 data is carried out, and calculated a regression formula and regression coefficient, the correlation coefficient, and the root mean square error. In Figure 3, three of the five sites (AKTOBE, ZHEZKAZGAN, PAVLODAR) have very good correlations, and the regression coefficient and correlation coefficient are almost close to 1. The CMIP6 data of the other two sites, ATYRAU and TARAZ, are smaller than the IGRA2 data; consider the locations of these two sites in Figure 1, ATYRAU is on the edge of the Caspian Sea and TARAZ is on the edge of the Pamir Plateau, both are present in the land cover transition zone with complex climate, it may cause the deviation in results. This indicates that TCWV obtained from the CanESM5, IPSL-CM6A-LR, MIROC6, and MRI-ESM2-0 models can be used to characterize the magnitude of TCWV in Central Asia. 

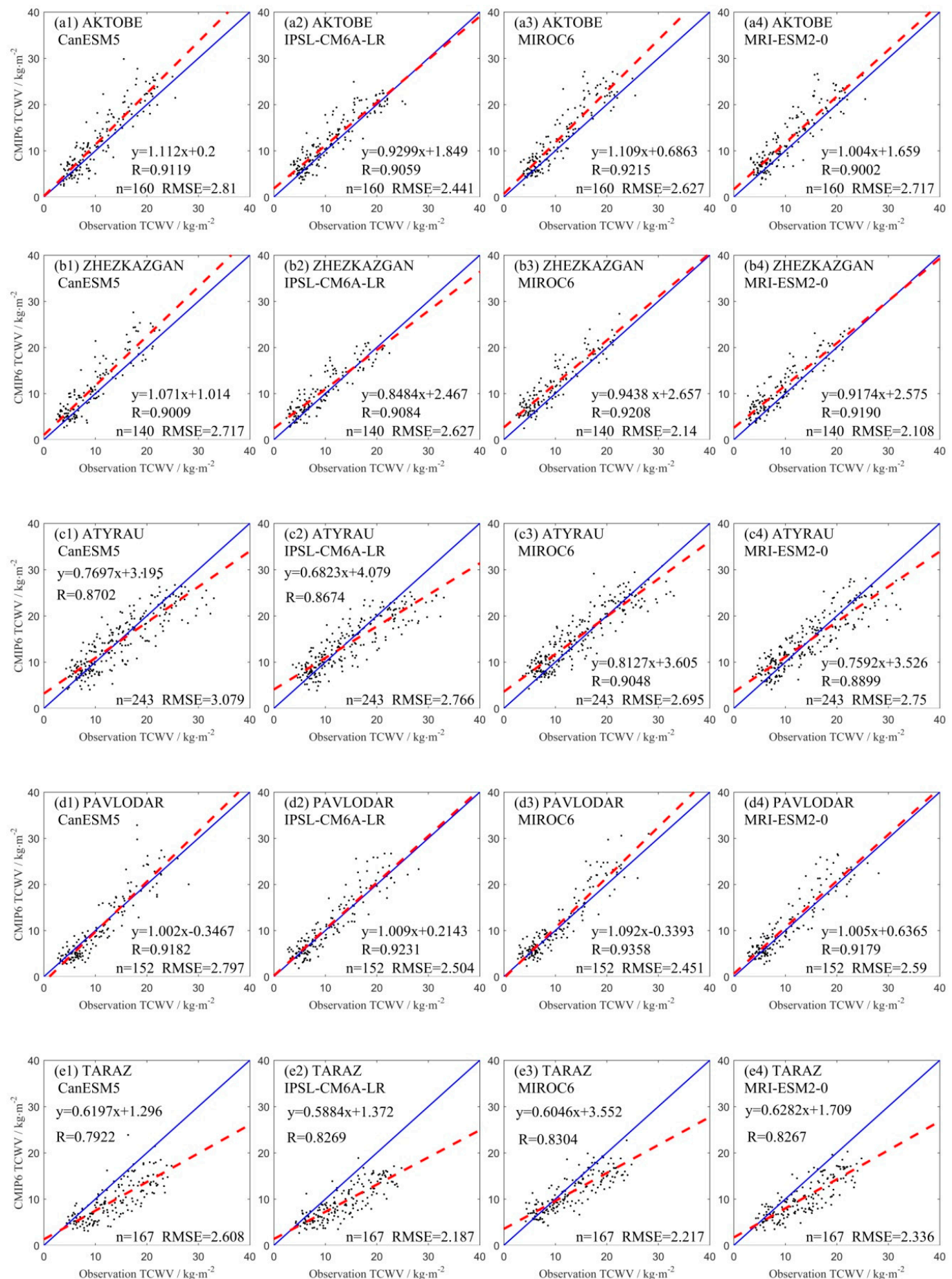

Figure 3. Scatter plot of monthly total column water vapor (TCWV) in historical CMIP6 four model's simulation against sounding stations measured TCWV at five stations: (a1-a4) AKTOBE, (b1-b4) ZHEZKAZGAN, (c1-c4) ATYRAU, (d1-d4) PAVLODAR, (e1-e4) TARAZ from 1979-2014 in Central Asia. Each column represents data from different stations compared within the same CMIP6 model. The solid line is the 1:1 line, and the dash one represents the 'regression line'. $\mathrm{n}$ represents the number of months actually used for comparison; RMSE is the root mean square error between the observed data and CMIP6 data.

\subsection{Historical TCWV for Reference Period 1986-2005}

The spatial distribution of annual TCWV from different GCMs during the baseline period (1986-2005) is shown in Figure 4. The spatial patterns of TCWV in the Central Asian region during 
the baseline period were similar, with the areal averaged value from the CanESM5 model being the smallest, with about $10.8 \mathrm{~mm}$, and the one from the MIROC6 model being the highest, with about $12.4 \mathrm{~mm}$. Spatially, TCWV is small in the east and large in the west. The column of atmosphere decreases with altitude, so the higher elevation region has smaller TCWV amount, while the lower elevation region has the higher TCWV amount. This is mainly related to the fact that TCWV amounts are obtained by integrating water vapor from the ground to the top of the atmosphere. With higher elevation, the air column is shorter, and the TCWV amount is naturally smaller. Moreover, the results showed that the lower elevations have large areas of water body, such as the Caspian Sea, which also contributed a lot to the local water vapor amount.
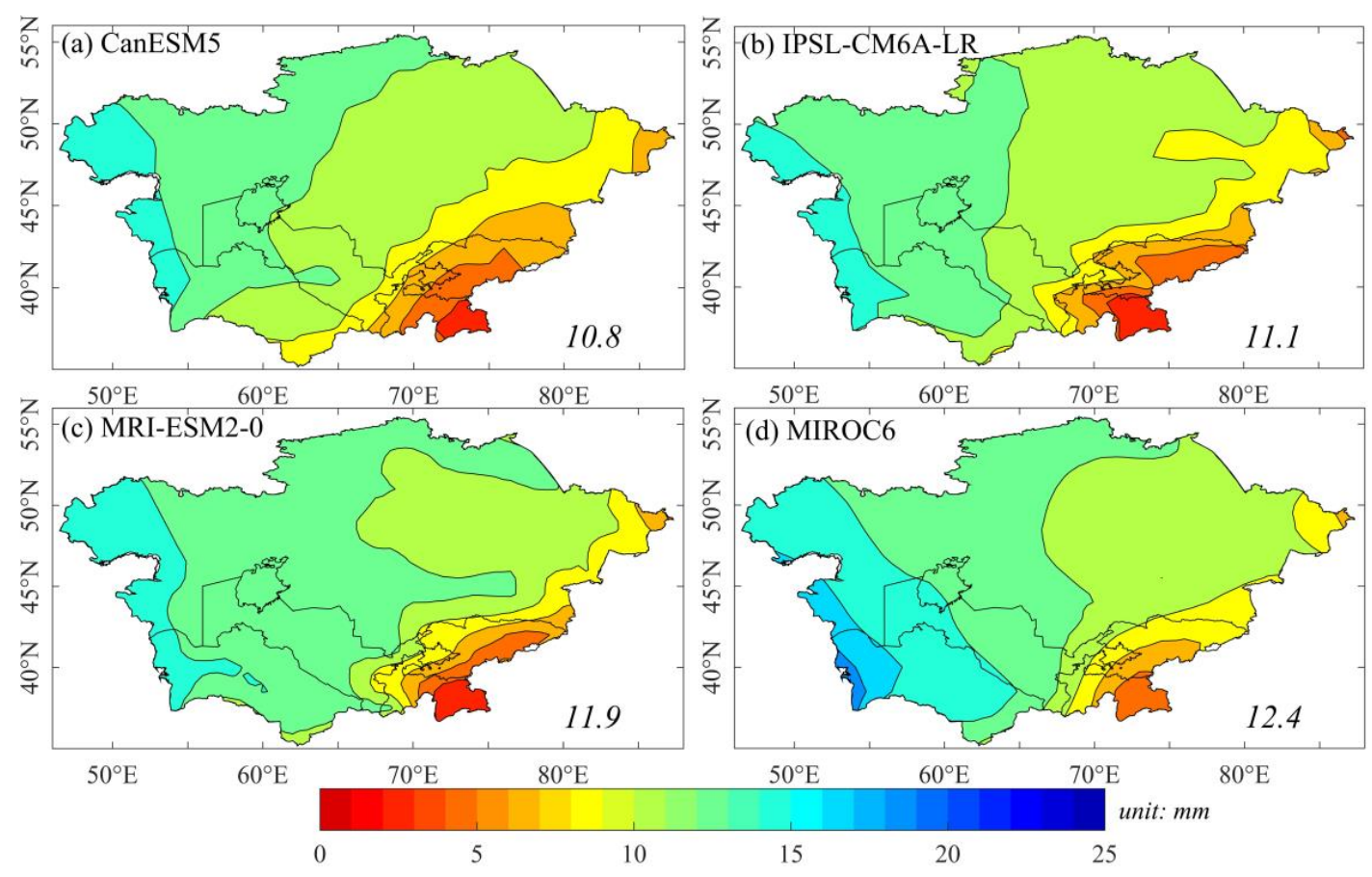

Figure 4. Spatial distribution of TCWV in Central Asia during the baseline period 1986-2005. The areal averaged TCWV for Central Asia is given at the bottom right of each panel (unit: $\mathrm{mm}$ ).

\subsection{Projected TCWV for $2021-2100$}

Taking Central Asia as a whole, the CMIP6 Multi Model Ensemble (MME) projected higher TCWV amounts during the period 2021-2100, relative to the baseline period 1986-2005, under the future scenarios SSP1-1.9, SSP1-2.6, SSP2-4.5, SSP3-7.0, SSP4-3.4, SSP4-6.0, and SSP5-8.5. Figure 5 shows the differences among the models. We define the uncertainty range of the climate models as the change between the maximum and minimum values of the four GCMs, and represented by light-colored bands in Figure 5. According to Figure 5a, the variation trend of TCWV by each scenario is roughly the same by 2040, with an increasing trend. After 2040, the projected TCWV under different scenarios begins to diverge. Under SSP1-1.9 and SSP1-2.6 scenarios, areal averaged TCWV will increase from 2021 to 2030, followed by a slight increase of nearly a decade, and then gradually decrease since the end of the 2030s, especially under SSP1-1.9 scenario. Under SSP4-3.4 scenario, the TCWV will grow from 2021 to 2055 by about $10 \%$, and then without significant changes until 2100 . Under SSP2-4.5 and SSP4-6.0 scenarios, TCWV will grow rapidly from 2021 to 2065 (by about 15\%), and after that show a lower growth rate from 2065 to 2100 , continued with an overall growth rate of about $5 \%$ relative to the baseline period (1986-2005). UnderSSP3-7.0 and SSP5-8.5 scenarios, a strong increasing trend is projected, with the largest and fastest increase in TCWV under SSP5-8.5. The SSP3-7.0 and SSP5-8.5 scenarios depict a rise from $5 \%$ in 2021 to $45 \%$ and $60 \%$, respectively, by the end of the 2090 s. 
As shown in Figure 5b, the trend of temperature in Central Asia is the same as TCWV. The change in Ts in Central Asia from 2021 to 2100 under different scenarios is highly consistent with the change in TCWV, indicating that temperature is most closely related to TCWV. Under SSP3-7.0 and SSP5-8.5 scenarios, the Ts increase in the most Central Asia with an increase of about $5.0{ }^{\circ} \mathrm{C}$ and $7.0{ }^{\circ} \mathrm{C}$, respectively, by the end of 2090s compared with 2020s, whereas it increases about $6.0^{\circ} \mathrm{C}$ and 8.0 ${ }^{\circ} \mathrm{C}$, respectively, by the end of 2090s, compared with the baseline period (1986-2005). Figure 5c, d visualize that the changes in precipitation and evapotranspiration in Central Asia from 2021 to 2100 are insignificant; it can be concluded that precipitation and evapotranspiration are not significantly related to TCWV.
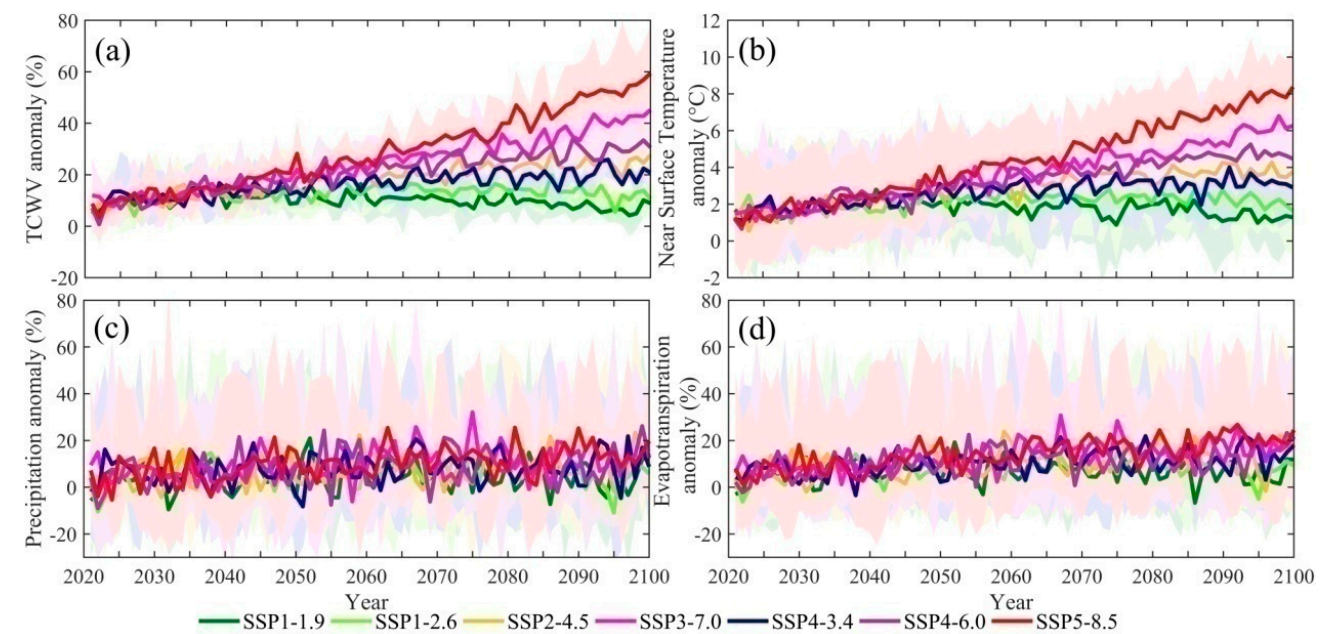

Figure 5. Anomaly time series of annual (a) TCWV, (b) near-surface temperature (Ts), (c) precipitation, and (d) evapotranspiration of Multi Model Ensemble (MME) mean values (relative to the 1986-2005 baseline period). The color shadows reflect the uncertainty range of climate models. The shading indicates the uncertainty range of simulation results by 4 CMIP6 models.

\subsection{Spatiotemporal Variation of Projected TCWV}

Figure 6 shows the changes of TCWV at four 20-year periods-2021-2040, 2041-2060, 2061-2080, and 2081-2100-under 7 scenarios. In comparison with Figure 5a, it is evident that the changes of TCWV in Central Asia in each period are significantly different from those in the baseline period (1986-2005).

Under SSP1-1.9 scenario, TCWV in Central Asia will increase slightly during the periods 2021-2040 and 2041-2060, and then falls back to the level of the 2020s during the periods 2061-2080 and 2081-2100. Under SSP1-2.6 scenario, TCWV will increase during the first three periods, and then decline 2081-2100. Under other scenarios, increases will continue through all periods, but with different amplitudes. In the case of SSP5-8.5, the continuous increase will be most rapid, with TCWV rising from $11.9 \%$ at 2021-2040 to $49.9 \%$ at 2081-2100, relative to the baseline period (1986-2005). The last three periods showed an accelerated growth relative to the previous period. In the case of SSP3-7.0, it will rise by $38.3 \%$ at 2081-2100 relative to the baseline period, which is lower than that in the case of SSP5-8.5, with no acceleration. For SSP2-4.5, SSP4-6.0, and SSP4-3.4 scenarios, the first three periods will show a growing trend, but with growth rate slowly down from the first three periods to 2081-2100. Combined with Figure $5 a, b$, it can be found that the increase in TCWV is related to the increase of air temperature, and it also rises with the radiative forcing level. According to the spatial characteristics of TCWV changes in Figure 6, it is obvious that the regions with high TCWV amounts, such as the low-elevation area around the Caspian Sea in the southwest, showed a small increase relative to the baseline period (1986-2005), while the regions with low TCWV amounts, such as the high-elevation areas in the southeast, have a substantial increase. The results show that the higher the altitude, the greater the increase of TCWV; the temporal variation of TCWV was different under different scenarios and different periods. One possible driving factor is that, with global warming, the water vapor transport between 
the ocean and the land is enhanced, and the long-distance water vapor transport mainly occurs above $850 \mathrm{hPa}$ (about $1500 \mathrm{~m}$ ); this height is the middle and upper troposphere. The atmospheric column at low altitude is thicker, and local water vapor accounts for a larger proportion of the TCWV, while the atmospheric column at high altitude is thinner and the value of TCWV is smaller, so it is more sensitive to the water vapor, which is transported over long distances. Therefore, the same outer region water vapor transported increases, resulting in a higher variation of greater proportion water vapor content in the high-altitude area.
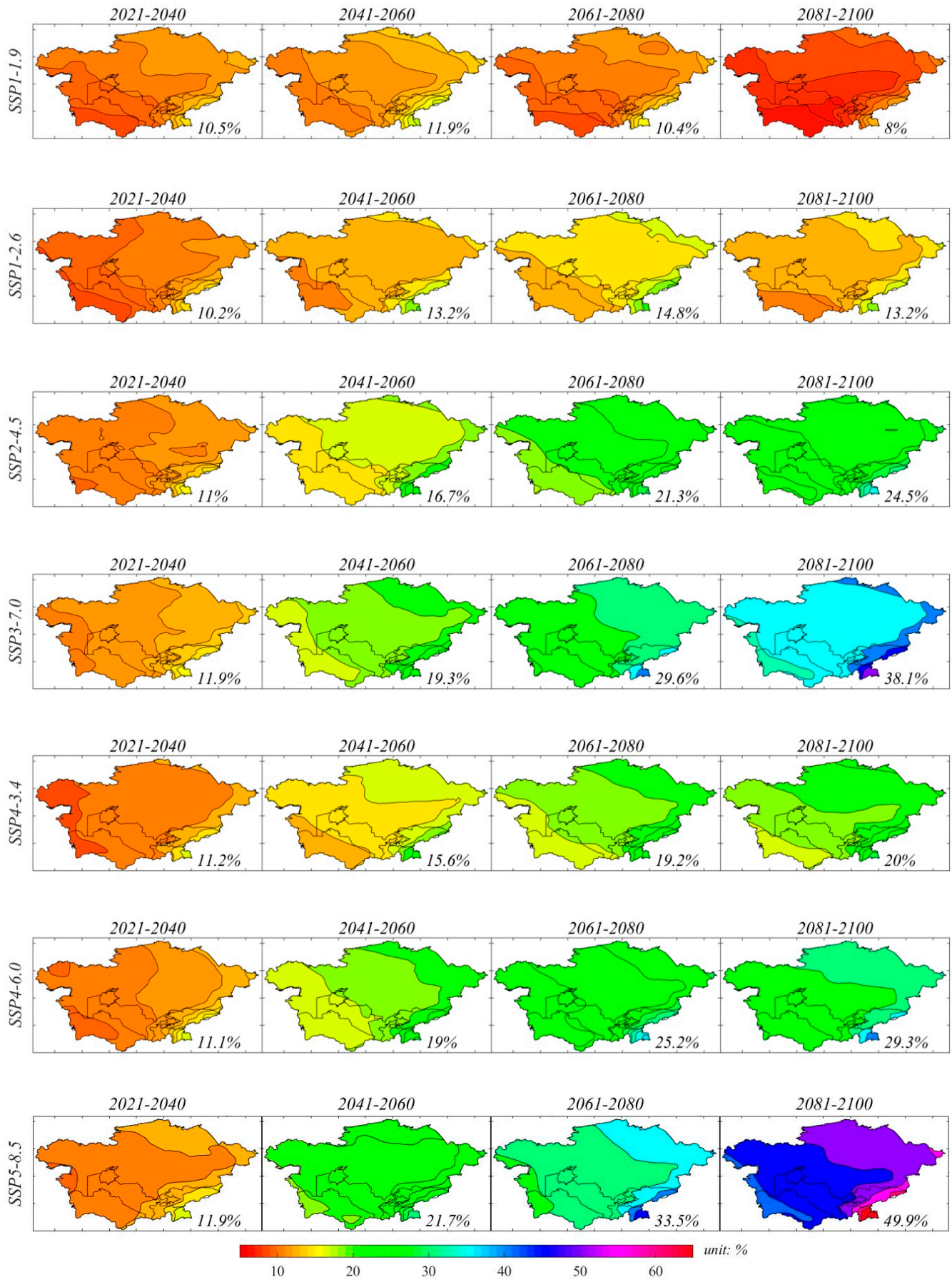

Figure 6. Spatial distribution of the change in TCWV amount in four 20-year periods (2021-2040, 2041-2060, 2061-2080, 2081-2100) under 7 future scenarios (SSP1-1.9, SSP1-2.6, SSP2-4.5, SSP3-7.0, SSP4-3.4, SSP4-6.0, SSP5-8.5), relative to the baseline period 1986-2005. The areal average TCWV growth rate for Central Asia is shown in the lower right corner of each panel. 


\subsection{The Relationship between TCWV Variation and Ts}

As the air moisture ratio in the upper troposphere increases with global warming, water vapor shows a strong positive feedback to temperature rise. Meanwhile, the specific humidity in the upper and middle troposphere remains roughly constant. One of the conclusions of the fifth IPCC assessment report is that the global atmospheric water vapor content increases by about $7 \%$ per $1{ }^{\circ} \mathrm{C}$ increase in air temperature, which is given by the Clausius-Clapeyron equation; however, both the global precipitation and evapotranspiration in global warming simulations increased by only $1 \%$ to $3 \%$ per 1 ${ }^{\circ} \mathrm{C}$ rise in air temperature [35,36].

In this study, a simple linear regression relationship was established between the increase in Ts (unit: ${ }^{\circ} \mathrm{C}$ ) and the percent increase in TCWV (unit: \%) in future, relative to the baseline period. The linear regression slope of the percentage increase in TCWV relative to the increase in Ts is the relation between the increasing amplitude of temperature and TCWV. Here, we have discussed the relationship between TCWV and Ts for Central Asia from 2021 to 2100, as shown in Figure 7. It represents the linear regression slope between the value of TCWV and the mean value of Ts from 2021 to 2100, relative to the baseline period. Under SSP1-2.6, SSP3-7.0, SSP2-4.5, and SSP5-8.5, the regression slope of the Central Asian region is positive, which matches the findings in Figures 5 and 6 . Moreover, as shown in Figure $7 \mathrm{f}$, the slope rises with the increase in Ts related to rising emission intensity, which indicates that the increase of TCWV is more closely related to Ts and radiative forcing than precipitation and evapotranspiration.

According to the Clausius-Clapeyron equation, for each $1{ }^{\circ} \mathrm{C}$ increase in temperature, the atmospheric water holding capacity increases by about $7 \%$ [22]. This means that the linear regression slope between percentage increase in TCWV and air temperature should be equal to 7 . As shown in Figure 7f, the mean slope for Central Asia is 6.6 under SSP5-8.5 scenario, followed by the mean slope of 6.4 under SSP3-7.0 scenario. This indicates that TCWV increases continuously under these two scenarios from 2021 to 2100 , and the regional average growth rate is close to the theoretical value from the Clausius-Clapeyron equation. The mean slopes under SSP2-4.5, SSP4-3.4, and SSP4-6.0 scenarios are all less than 7 . The smaller slope is related to the inconsistent growth rate in TCWV and Ts during the different periods (Figures $5 \mathrm{a}$ and 6 ).

Under all scenarios, the TCWV increase has a similar spatial distribution as the temperature slope. The regional slope value ranges from 2 to 10, and the slope is steeper in the low-elevation areas around the Caspian Sea in the southwest of Central Asia, and the high-elevation areas in the southeast. The higher the air temperature caused by higher radiative forcing, the more obvious this feature is.

The relationship between TCWV and Ts is the most significant under SSP5-8.5 scenario. In all future scenarios, with the increase in radiative forcing, the area of high correlation increases, and the slope becomes steeper. Especially under SSP3-7.0 and SSP5-8.5 scenarios, it can be found that the slopes are steeper in the low-elevation areas around the Caspian Sea in the west of Central Asia, the Pamir Plateau in the southeast, and the Altay mountains in the northeast. This is mainly related to the distribution of water resources in Central Asia. The Caspian Sea in the southwest is the largest inland lake in the world, and there is an abundance of water for evapotranspiration. In the eastern mountains, there is a large number of glaciers [37-39], and the increase in glacial melting water can also provide water for evapotranspiration. In the future, the increase in local evapotranspiration intensity will greatly increase the TCWV amount. This result is consistent with the studies by Zhang et al. [40], who apply CMIP5 MME to show a very high correlation between TCWV and Ts in high-elevation areas such as the Qinghai-Tibet plateau. In terms of the physical mechanism, TCWV should be more closely related to the temperature of the lower troposphere than to the temperature of the near surface air [8]. 

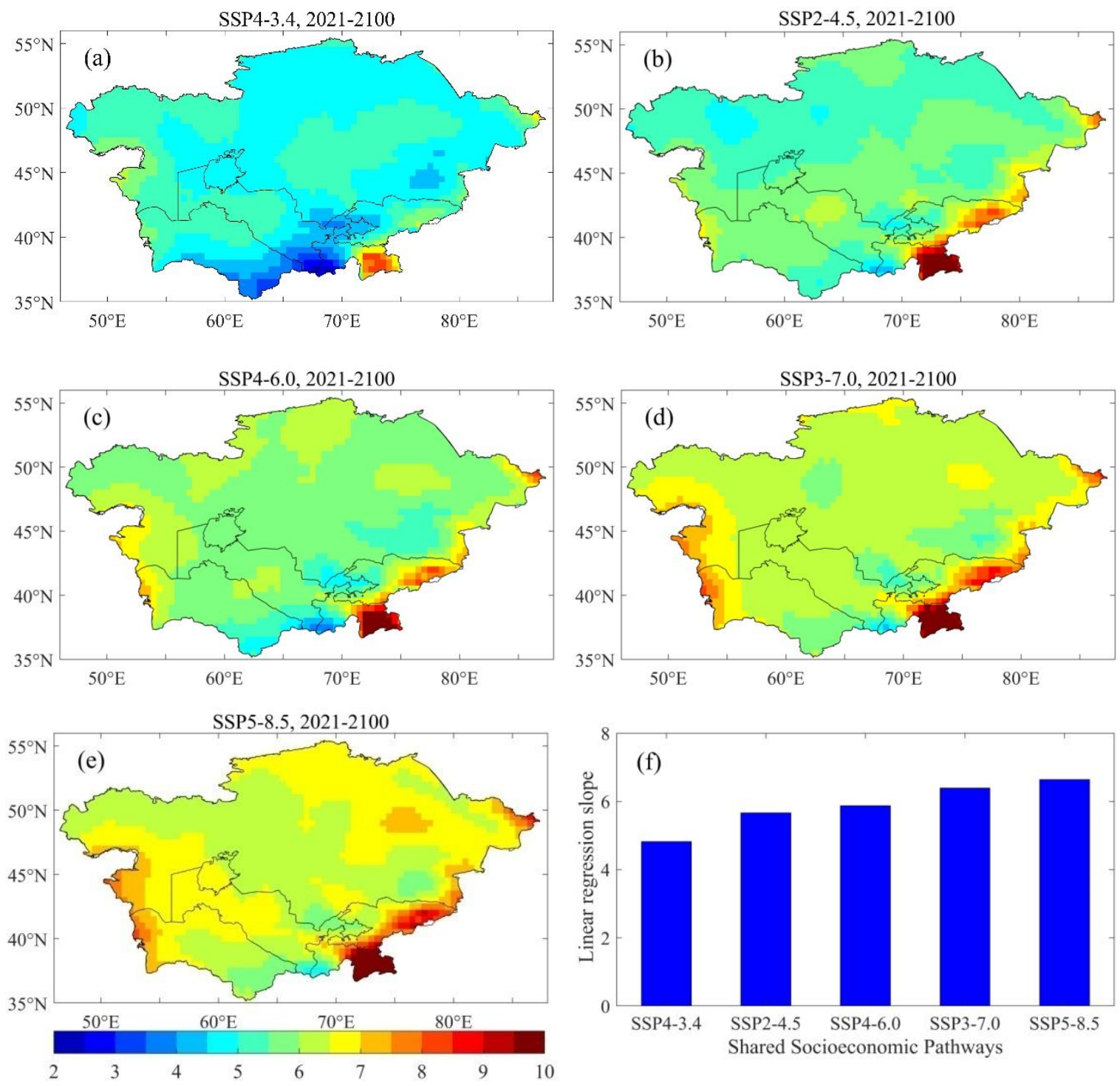

Figure 7. The linear regression slope between the mean increase in TCWV $(\%)$ and $\mathrm{Ts}\left({ }^{\circ} \mathrm{C}\right)$ from the MME for the period from 2021 to 2100, relative to the baseline period (1986-2005): (a) SSP4-3.4, (b) SSP2-4.5, (c) SSP4-6.0, (d) SSP3-7.0, (e) SSP5-8.5, and (f) average of linear regression slope under five scenarios.

\section{Summary and Conclusions}

In this study, the climatic characteristics of water vapor change in Central Asia are studied by using the TCWV, temperature, precipitation, and evapotranspiration data from four global climate models in CMIP6, under seven future scenarios. The major conclusions are summarized below:

(1) The four climate models are consistent in the simulation of TCWV in Central Asia, and with the measured sounding monthly data. The linear correlation analysis of IGRA2 data and CMIP6 data showed that three of the five sites have very good correlations, but CMIP6 data are smaller than the IGRA2 at other two sites. This indicates that TCWV obtained from the four CMIP6 models can be used to characterize the magnitude of TCWV in Central Asia.

(2) The spatial distribution of TCWV in the four CMIP6 climate models during the historical simulation baseline period (1986-2005) has the same pattern. High TCWV amounts are found in the west around the Caspian Sea, Lake Aral and in other low-elevation areas, while low amounts 
are distributed over the southeast Pamir Plateau and other high-elevation areas. The areal average value in Central Asia is between $10.8 \mathrm{~mm}$ and $12.4 \mathrm{~mm}$, depending on the model.

(3) On the whole, TCWV in Central Asia will increase indifferent scenarios from 2021 to 2040, and the trends begin to diverge after 2040. The average TCWV will increase during 2021-2050 under SSP1-1.9 and SSP1-2.6 scenarios, and then decrease gradually after 2050. In SSP4-3.4 scenario, TCWV will continue to grow from 2021 to 2055, and then stay constant until 2100. Under SSP2-4.5 and SSP4-6.0 scenarios, TCWV will rise rapidly from 2021 to 2065, but the growth will slow down from 2065 to 2100 . Under SSP3-7.0 and SSP5-8.5 scenarios, TCWV will exhibit a continuously increasing trend, with the largest increase and the fastest growth under SSP5-8.5. This indicates a strong relationship between temperature and TCWV, while the relationship between precipitation/evapotranspiration and TCWV is less prominent. This is mainly due to the fact that arid and semi-arid climate dominates in most regions of Central Asia, and low precipitation limiting the evapotranspiration. It can be assumed that the increase in TCWV in Central Asia is mainly due to the increase in the atmospheric water holding capacity caused by global warming.

(4) During the four time periods 2021-2040, 2041-2060, 2061-2080, and 2081-2100, changes in TCWV are obviously different under the seven scenarios in Central Asia. The most prominent feature of TCWV change is that its growth is closely related to the altitude; the higher the elevation, the greater the TCWV increase will be.

(5) Under the future scenarios SSP2-4.5, SSP3-7.0, SSP4-3.4, SSP4-6.0, and SSP5-8.5, it can be seen that the higher the radiative forcing, the steeper the regression slope is between TCWV and temperature changes; that is, the faster the increase. Under SSP3-7.0 and SSP5-8.5 scenarios, the trend slope is close to the theoretical value of the Clausius-Clapeyron equation.

Author Contributions: Conceptualization, Z.L., B.S., and T.J.; Methodology, Z.L., B.S. and T.J.; Formal Analysis, H.T., Y.W., H.H.; Contributed to the writing of the manuscript: Z.L., H.T., H.H., B.S., Y.W., T.J.; Analyzed the data and Visualization, Z.L. All authors have read and agreed to the published version of the manuscript.

Funding: This research was funded by the National Key Research and Development Program of China (2018FY100501), National Natural Science Foundation of China (41971023) and CAS "Light of West China" Program (2019-XBQNXZ-B-004).

Acknowledgments: The IGRA2 data are provided by the NCDC from their website at https://www1.ncdc.noaa. gov/pub/data/igra/. The CMIP6 model data were obtained from the website of World Climate Research Program (https://esgf-node.llnl.gov/search/cmip6/).

Conflicts of Interest: The authors declare no conflict of interest.

\section{References}

1. IPCC; Field, C.B.; Barros, V.R.; Dokken, D.J.; Mastrandrea, M.D.; Mach, K.J.; Abdrabo, M.A.-K.; Adger, W.N.; Anokhin, Y.A.; Anisimov, O.A.; et al. Part A: Global and Sectoral Aspects. Contribution of Working Group II to the Fifth Assessment Report of the Intergovernmental Panel on Climate Change. In Climate Change 2014: Impacts, Adaptation, and Vulnerability; Cambridge University Press: Cambridge, UK; New York, NY, USA, 2014; p. 1132.

2. Chen, F.H.; Chen, J.H.; Holmes, J.; Boomer, I.; Austin, P.; Gates, J.B.; Wang, N.-L.; Brooks, S.J.; Zhang, J.-W. Moisture changes over the last millennium in arid central Asia: A review, synthesis and comparison with monsoon region. Quat. Sci. Rev. 2010, 29, 1055-1068. [CrossRef]

3. Folland, C.K.; Rayner, N.A.; Brown, S.J.; Smith, T.M.; Shen, S.S.P.; Parker, D.E.; Macadam, I.; Jones, P.D.; Jones, R.; Nicholls, N.; et al. Global temperature change and its uncertainties since 1861. Geophys. Res. Lett. 2001, 28, 2621-2624. [CrossRef]

4. Hansen, J.; Lacis, A.; Rind, D.; Russell, G.; Stone, P.; Fung, I.; Ruedy, R.; Lerner, J. Climate sensitivity: Analysis of feedback mechanisms. Geophys. Monogr. Ser. 1984, 29, 130-163. [CrossRef]

5. Turco, R.P. Upper atmosphere aerosols: Properties and natural cycles. In The Atmospheric Effects of Stratospheric Aircraft: A First Program Report; Nasa Reference Publication: Hampton, VA, USA, 1992; Volume 1272, pp. $63-82$. 
6. Held, I.M.; Soden, B.J. Water vapor feedback and global warming. Annu. Rev. Energy Environ. 2000, 25, 441-475. [CrossRef]

7. Trenberth, K.E.; Hurrell, J.W.; Stepaniak, D.P. The Asian Monsoon: Global Perspective. In The Asian Monsoon; Springer: New York, NY, USA, 2006; pp. 67-87.

8. Zhao, T.B.; Dai, A.G.; Wang, J.H. Trends in tropospheric humidity from 1970 to 2008 over China from a homogenized radiosonde dataset. J. Clim. 2012, 25, 4549-4567. [CrossRef]

9. Kiehl, J.T.; Trenberth, K.E. Earth's annual global mean energy budget. Bull. Am. Meteorol. Soc. 1997, 78, 197-208. [CrossRef]

10. Trenberth, K.E. Changes in precipitation with climate change. Clim. Res. 2011, 47, 123-138. [CrossRef]

11. Trenberth, K.E.; Fasullo, J.; Smith, L. Trends and variability in column-integrated atmospheric water vapor. Clim. Dyn. 2005, 24, 741-758. [CrossRef]

12. IPCC; Stocker, T.S.; Qin, D.; Plattner, G.K.; Tignor, M.M.B.; Allen, S.K.; Boschung, J.; Nauels, A.; Xia, Y.; Bex, V.; et al. Contribution of Working Group I to the Fifth Assessment Report of the Intergovernmental Panel on Climate Change. In Climate Change 2013: The Physical Science Basis; Cambridge University Press: Cambridge, UK; New York, NY, USA, 2013; p. 1535.

13. Abuduwaili, J.; Gulnura, I.; Saparov, G. Water Resources Development and Management. In Hydrology and Limnology of Central Asia; Springer Nature: Singapore; Pte Ltd.: Singapore, 2019. [CrossRef]

14. Eyring, V.; Bony, S.; Meeh, G.A.; Senior, C.A.; Stevens, B.; Stouffer, R.J.; Taylor, K.E. Overview of the Coupled Model Intercomparison Project Phase 6 (CMIP6) experimental design and organization. Geosci. Model Dev. 2016, 9, 1937-1958. [CrossRef]

15. O’Neill, B.C.; Tebaldi, C.; van Vuuren, D.P.; Eyring, V.; Friedlingstein, P.; Hurtt, G.; Knutti, R.; Kriegler, E.; Lamarque, J.-F.; Lowe, J.; et al. The Scenario Model Intercomparison Project (ScenarioMIP) for CMIP6. Geosci. Model Dev. 2016, 9, 3461-3482. [CrossRef]

16. O’Neill, B.C.; Kriegler, E.; Riahi, K.; Ebi, K.L.; Hallegatte, S.; Carter, T.R.; Mathur, R.; Van Vuuren, D. A new scenario framework for climate change research: The concept of shared socioeconomic pathways. Clim. Chang. 2014, 122, 387-400. [CrossRef]

17. O’Neill, B.C.; Kriegler, E.; Ebi, K.L.; Kemp-Benedict, E.; Riahi, K.; Rothman, D.S.; Van Ruijven, B.J.; Van Vuuren, D.; Birkmann, J.; Kok, K.; et al. The roads ahead: Narratives for shared socioeconomic pathways describing world futures in the 21st century. Glob. Environ. Chang. 2017, 42, 169-180. [CrossRef]

18. Liao, W.L.; Liu, X.P.; Xu, X.Y.; Chen, G.; Liang, X.; Zhang, H.; Li, X. Projections of land use changes under the plant functional type classification in different SSP-RCP scenarios in China. Sci. Bull. 2020. [CrossRef]

19. Zhang, L.X.; Chen, X.L.; Xin, X.G. Short commentary on CMIP6 Scenario Model Intercomparison Project (ScenarioMIP). Clim. Chang. Res. 2019, 15, 519-525. (In Chinese) [CrossRef]

20. Chen, F.H.; Wang, J.S.; Jin, L.Y.; Zhang, Q.; Li, J.; Chen, J. Rapid warming in mid-latitude central Asia for the past 100 years. Front. Earth Sci. China 2009, 3, 42-50. [CrossRef]

21. Hu, Z.Y.; Zhang, C.; Hu, Q.; Tian, H. Temperature changes in Central Asia from 1979 to 2011 based on multiple datasets. J. Clim. 2014, 27, 1143-1167. [CrossRef]

22. Trenberth, K.E.; Dai, A.G.; Rasmussen, R.M.; Parsons, D. The changing character of precipitation of precipitation. BAMS 2003, 84, 1205-1217. [CrossRef]

23. Shi, L.; Bates, J.J. Three decades of intersatellite-calibrated High-Resolution Infrared Radiation Sounder upper tropospheric water vapor. J. Geophys. Res. 2011, 116, D04108. [CrossRef]

24. Glantz, M.H. Water, climate, and development issues in the Amu Darya basin. Mitig. Adapt. Strateg. Glob. Chang. 2005, 10, 23-50. [CrossRef]

25. Lioubimtseva, E.; Henebry, G.M. Climate and environmental change in arid Central Asia: Impacts, vulnerability, and adaptations. J. Arid Environ. 2009, 73, 963-977. [CrossRef]

26. Yin, Z.Y.; Wang, H.L.; Liu, X.D. A Comparative study on precipitation climatology and interannual variability in the lower mid-latitude East Asia and Central Asia. J. Clim. 2014, 27, 7830-7848. [CrossRef]

27. Zonn, I.S.; Zhiltsov, S.S.; Kostianoy, A.G.; Semenov, A.V. Water resources management in Central Asia. Handb. Environ. Chem. 2020, 105, 31-46. [CrossRef]

28. Narama, C.; Kääb, A.; Duishonakunov, M.; Abdrakhmatov, A. Spatial variability of recent glacier area changes in the Tien Shan Mountains, Central Asia, using Corona ( 1970), Landsat ( 2000), and ALOS ( 2007) satellite data. Glob. Planet. Chang. 2010, 71, 42-54. [CrossRef] 
29. Deng, M.J.; Long, A.H.; Zhang, Y.; Li, X.; Lei, Y. Assessment of water resources development and utilization in the five Central Asia countries. Adv. Earth Sci. 2010, 25, 1347-1356. (In Chinese)

30. Zhou, H.F.; Zhang, J.B. Analysis on the volume of available water resources and its carrying capacity in Xinjiang, China. Arid Land Geogr. 2005, 28, 756-763. (In Chinese)

31. Jiang, J.; Zhou, T.; Zhang, W. Evaluation of satellite and reanalysis precipitable water vapor data sets against radiosonde observations in central Asia. Earth Space Sci. 2019, 6, 1129-1148. [CrossRef]

32. Yang, Q.; Liu, X.Y.; Cui, C.X.; Jun, L.I.; Rui, L. The Computation and Characteristics Analysis of Water Vapor Contents in the Tarim Basin, China. Acta Geogr. Sin. 2010, 65, 853-862. (In Chinese) [CrossRef]

33. Sheng, P.X.; Mao, J.T.; Li, J.G.; Zhang, A.C.; Sang, J.G.; Pan, N.X. Atmospheric Physics; Peking University Press: Beijing, China, 2003.

34. Masson-Delmotte, V.; Zhai, P.X.; Pörtner, H.O.; Roberts, D.; Skea, J.; Shukla, P.R.; Pirani, A.; Moufouma-Okia, W.; Péan, C.; Pidcock, R.; et al. An IPCC Special Report on the Impacts of Global Warming of $1.5^{\circ} \mathrm{C}$ above Pre-Industrial Levels and Related Global Greenhouse Gas Emission Pathways, in the Context of Strengthening the Global Response to the Threat of Climate Change, Sustainable Development, and Efforts to Eradicate Poverty; IPCC: Geneva, Switzerland, 2018.

35. Lambert, F.H.; Webb, M.J. Dependency of global mean precipitation on surface temperature. Geophys. Res. Lett. 2008, 35, L16706. [CrossRef]

36. Lu, J.; Cai, M. Stabilization of the atmospheric boundary layer and the muted global hydrological cycle response to global warming. J. Hydrometeor 2009, 10, 347-352. [CrossRef]

37. Yao, T.D.; Wang, Y.Q.; Liu, S.Y.; Pu, J.; Shen, Y.; Lu, A. Recent glacial retreat in High Asia in China and its impact on water resource in Northwest China. Sci. China Ser. D Earth Sci. 2004, 47, 1065-1075. [CrossRef]

38. Siegfried, T.; Bernauer, T.; Guiennet, R.; Sellars, S.; Robertson, A.W.; Mankin, J.S.; Bauer-Gottwein, P.; Yakovlev, A. Will climate change exacerbate water stress in Central Asia? Clim. Chang. 2012, 112, 881-899. [CrossRef]

39. Unger-Shayesteh, K.; Vorogushyn, S.; Farinotti, D.; Gafurov, A.; Duethmann, D.; Mandychev, A.; Merz, B. What do we know about past changes in the water cycle of Central Asian headwaters? A review. Glob. Planet. Chang. 2013, 110, 4-25. [CrossRef]

40. Zhang, J.P.; Zhao, T.B. Historical and future changes of atmospheric precipitable water over China simulated by CMIP5 models. Clim. Dyn. 2019, 52, 6969-6988. [CrossRef] 